\title{
Toxic levels of ammonia in human brain abscess
}

\author{
Daniel Dahlberg, MD, ${ }^{1}$ Jugoslav Ivanovic, MD, ${ }^{1}$ and Bjørnar Hassel, MD, PhD²,3 \\ Departments of ${ }^{1}$ Neurosurgery and ${ }^{2}$ Complex Neurology and Neurohabilitation, Oslo University Hospital, Oslo; and ${ }^{3}$ Norwegian \\ Defence Research Establishment (FFI), Kjeller, Norway
}

\begin{abstract}
OBJECTIVE Brain abscesses could lead to cerebral symptoms through tissue destruction, edema, changes in brain architecture, and increased intracranial pressure. However, the possibility that the pus itself could contribute to symptoms has received little attention. Brain abscesses are areas of tissue destruction, proteolysis, and formation of free amino acids, which are energy substrates for bacteria and possible sources of ammonia. Ammonia is neurotoxic, may cause brain edema, and could contribute to the symptoms of brain abscesses.
\end{abstract}

METHODS The authors analyzed the extracellular phase of pus from 14 patients with brain abscesses with respect to ammonia and amino acids. For comparison, CSF from 10 patients undergoing external ventricular drainage was included. The ammonia-forming ability of Streptococcus intermedius and Staphylococcus aureus, two common microbial isolates in brain abscesses, was studied in vitro.

RESULTS In brain abscesses ammonia was $15.5 \mathrm{mmol} / \mathrm{L}$ (median value; range 1.7-69.2 mmol/L). In CSF ammonia was $29 \mu \mathrm{mol} / \mathrm{L}$ (range 17-55 $\mathrm{mmol} / \mathrm{L}$; difference from value in pus: $p<0.001$ ). The total concentration of amino acids in brain abscesses was 1.12-16 times higher than the ammonia concentration $(p=0.011)$. The median glucose value in pus was $0 \mathrm{mmol} / \mathrm{L}$ (range 0-2.1 mmol/L), lactate was $21 \mathrm{mmol} / \mathrm{L}$ (range 3.3-26.5 mmol/L), and pH was 6.8 (range 6.2-7.3). In vitro, S. intermedius and $S$. aureus formed ammonia at $6-7 \mathrm{mmol} / \mathrm{L}$ in 24 hours when incubated with 20 proteinogenic amino acids plus $\gamma$-aminobutyric acid (GABA), taurine, and glutathione at $1 \mathrm{mmol} / \mathrm{L}$.

CONCLUSIONS Intracerebral abscesses contain toxic levels of ammonia. At the concentrations found in pus, ammonia could contribute to the brain edema and the symptoms of brain abscesses.

http://thejns.org/doi/abs/10.3171/2015.1.JNS142582

KEY WORDS brain abscess; ammonia; cerebrospinal fluid; amino acids; lactate; infection

A BRAIN abscess could lead to cerebral symptoms by causing tissue destruction and edema as well as changes in brain architecture and intracranial pressure, but the possibility that the pus itself could contribute to symptoms has received little attention. However, brain abscesses have been shown to contain amino acids at high concentrations. ${ }^{9,15,19}$ Amino acids are energy substrates for bacteria, ${ }^{26}$ and bacterial metabolism of amino acids entails formation of ammonia; ${ }^{6}$ therefore, brain abscesses could contain ammonia. Ammonia is neurotoxic; its deleterious effects on the brain, as can be seen in hyperammonemic states, include vasogenic edema formation, ${ }^{35}$ astro- cytic swelling and alterations in neurotransmission, ${ }^{14,22,33}$ impaired astrocytic potassium handling, ${ }^{34}$ and a host of biochemical effects ${ }^{18}$ that could contribute to the various symptoms of hyperammonemic disorders. ${ }^{20}$

To see if brain abscesses contain ammonia we determined the extracellular concentration of ammonia in pus from patients with brain abscesses and, for comparison, in CSF from patients with external cerebroventricular drains. The ability of Streptococcus intermedius and Staphylococcus aureus, two common microbial causes of brain abscesses in humans, ${ }^{4,11}$ to produce ammonia from amino acids was investigated in vitro.

ABBREVIATIONS GABA $=\gamma$-aminobutyric acid; GSH = glutathione, reduced form; HPLC = high-performance liquid chromatography; $\mathrm{OD}_{600}=0$ optical density at $600 \mathrm{~nm}$. SUBMITTED November 11, 2014. ACCEPTED January 14, 2015.

INCLUDE WHEN CITING Published online August 14, 2015; DOI: 10.3171/2015.1.JNS142582. 


\section{Methods}

\section{Patients and Samples}

The study was approved by the Regional Ethics Committee for Medical Research in the southern and eastern part of Norway. Patients were recruited from 2011 to 2014. Informed, written consent was obtained from all participants or (in the case of children) their parents, in accordance with the Declaration of Helsinki. Pus from 14 patients with brain abscesses was collected at surgery. Nine of these patients were recently described with respect to amino acid levels in pus, clinical symptoms, and microbiological findings. ${ }^{9}$ The CSF used for the comparison was from 10 patients undergoing drainage of the cerebral ventricles through an external ventricular drain as part of the treatment for increased intracranial pressure. Of these patients, who were recently described with respect to amino acid levels in $\mathrm{CSF}^{9}$ (permission to reuse data granted by Elsevier), 6 had suffered subarachnoid hemorrhage, 3 had brain tumors, and 1 had congenital hydrocephalus. Intracranial pressure was normal at the time of sampling, and CSF was clear and colorless. Samples were aspirated into polypropylene syringes, cooled on ice, and rapidly centrifuged at $3000 \mathrm{~g}$ for 10 minutes at $4^{\circ} \mathrm{C}$. Supernatants were removed and stored at $-70^{\circ} \mathrm{C}$ until analysis, which in most cases took place within 4 hours. Prior to surgery, patients underwent MRI or CT scans of the brain. Volumes of abscesses were calculated from the MR or CT images, using the ellipsoid formula., ${ }^{9,27}$ Pus samples from all patients with brain abscess underwent culture and analysis by polymerase chain reaction for microbiological diagnosis, and pus smears were investigated by light microscopy after May-Grünewald-Giemsa staining. ${ }^{23}$

\section{In Vitro Formation of Ammonia From Amino Acids}

The $S$. intermedius and $S$. aureus used in the study were from The Culture Collection, University of Göteborg, Sweden (Catalog Nos. CCUG 43515 and CCUG 46923, respectively). The bacteria were grown on blood agar for 16 hours and suspended at approximately $10 \mu \mathrm{l}$ bacteria/200 $\mu$ l phosphate-buffered saline. A solution was made of all 20 proteinogenic amino acids plus $\gamma$-aminobutyric acid (GABA), taurine, and reduced glutathione (GSH) at $1 \mathrm{mmol} / \mathrm{L}$ in $(\mathrm{mmol} / \mathrm{L}) \mathrm{NaCl} 125, \mathrm{NaHCO}_{3} 25, \mathrm{KCl} 2.8$, $\mathrm{MgCl}_{2} 1, \mathrm{CaCl}_{2} 1$, and $\mathrm{NaH}_{2} \mathrm{PO}_{4} 0.3 ; \mathrm{pH}$ was 7.3 . The GSH was included, because it is present in the brain at approximately $1 \mathrm{mmol} / \mathrm{L} .{ }^{40}$ In some experiments a single amino acid was omitted from the amino acid solution to study its importance for ammonia formation. Glucose was not added, and to mimic anaerobic conditions, solutions were not saturated with oxygen. A similar solution, but with $\mathrm{pH}$ 6.5 to mimic the acid conditions in pus, was made, but results were similar to those obtained with a solution with $\mathrm{pH} 7.3$, so only the latter are given here. The amino acid concentrations were chosen on the basis of a previous study documenting millimolar concentrations of amino acids in brain abscesses. ${ }^{9}$ Bacterial suspensions were diluted in the amino acid solution at $10 \mu \mathrm{l} / \mathrm{ml}$ and adjusted to an optical density at $600 \mathrm{~nm}\left(\mathrm{OD}_{600}\right)$ of 0.28 for both streptococci and staphylococci. At 0, 1, 4, and 24 hours, samples were taken for analysis of ammonia and amino acids.

\section{Biochemical Analyses}

Ammonia was analyzed by spectrophotometry, using a Vitros DT60 II spectrophotometer (Ortho-Clinical Diagnostics). The method was linear in the range 10-500 $\mu \mathrm{mol} / \mathrm{L} ; \mathrm{r}=0.999 ; \mathrm{p}=4 \times 10^{-8}$, Pearson's test. Samples with ammonia concentrations above the detection limit were diluted with distilled water, as recommended by the manufacturer. Three pus samples were analyzed for ammonia by both indirect potentiometry with an ammonium-selective electrode (Modular P800, Roche) and by reflectance spectrophotometry (Vitros DT60 II spectrophotometer). The values obtained (24-36 mmol ammonia/L) with reflectance spectrophotometry were $99 \% \pm 9 \%($ mean $\pm \mathrm{SD})$ of the values obtained by indirect potentiometry. To see if amino acids could produce false ammonia measurements, ammonia was measured in $20 \mathrm{mmol} / \mathrm{L}$ solutions of all 20 proteinogenic amino acids, GABA, taurine, hypotaurine, and GSH. In none of the solutions was there an ammonia signal detected by reflectance spectrophotometry; this was true also for a solution of urea at $100 \mathrm{mmol} / \mathrm{L}$.

Amino acids were analyzed by high-performance liquid chromatography (HPLC) and fluorescence detection after precolumn derivatization with $o$-phthaldialdehyde, using an 1100 series HPLC unit (Agilent), as described previously. ${ }^{9}$

Supernatants of brain abscess pus were analyzed by reflectance spectrophotometry for glucose and lactate as described previously, ${ }^{17}$ and $\mathrm{pH}$ was measured with a $\mathrm{pH}$ meter (inoLab pH 7110, WTW GmbH) that was calibrated before each reading.

\section{Data Presentation and Statistics}

Values for amino acids in abscess pus were not normally distributed according to the Kolmogorov-Smirnov normality test. Therefore, all data are presented as median values with full range (minimum and maximum values). For the same reason groups were compared statistically, using the Kruskal-Wallis and Dunn tests for multiple comparisons, or the Wilcoxon matched-pairs signed-rank test, as appropriate. In vitro data on ammonia formation from amino acids were analyzed by 1-way ANOVA with the Dunnett test for multiple comparisons or a Newman-Keuls all pairwise comparison, as appropriate. A p value $<0.05$ was considered significant.

\section{Results}

\section{Focal and General Brain Abscess Symptoms- Microbiology}

All 14 patients with brain abscess had cerebral symptoms of varying severity (Table 1). Most symptoms were focal, reflecting the localization of the abscess. Eight patients had seizures, of whom 7 had focal seizures; in 1 patient only generalized seizures were observed. Five patients were disoriented. None of the patients were comatose. All patients had pronounced perilesional vasogenic edema, as could be seen on CT or MRI scans of the brain.

Light microscopy detected an abundance of polymorphonuclear leukocytes in all brain abscess samples, confirming the presence of pus. In pus from 8 patients, microbiological analysis identified $S$. intermedius; in 3 patients 
TABLE 1. Individual data in 14 patients with brain abscess*

\begin{tabular}{|c|c|c|c|c|c|c|}
\hline $\begin{array}{c}\text { Age (yrs), } \\
\text { Sex }\end{array}$ & Symptoms & Localization & Microbiology Findings & $\begin{array}{c}\text { Ammonia } \\
(\mathrm{mmol} / \mathrm{L})\end{array}$ & $\begin{array}{c}\text { Amino Acids } \\
(\mathrm{mmol} / \mathrm{L})\end{array}$ & Vol $\left(\mathrm{cm}^{3}\right)$ \\
\hline $58, \mathrm{~F}$ & Disorientation, rt-sided paresis & Lt frontal lobe & S. intermedius & 69.2 & 94.2 & 5.4 \\
\hline $72, \mathrm{M}$ & Seizures \& paresis It leg & Rt frontal lobe & $\begin{array}{l}\text { A. aphrophilus, } P \text {. micra, } P \text {. acnes, } \\
\text { F. nucleatum }\end{array}$ & 38.8 & 58.8 & 12 \\
\hline $62, \mathrm{~F}$ & Headache, disorientation & Lt cerebellar & S. intermedius & 36.4 & 65.2 & 8.2 \\
\hline $55, \mathrm{~F}$ & Seizures, headache & Rt parietal lobe & S. intermedius & 33.9 & 70.0 & 19 \\
\hline $21, \mathrm{M}$ & Disorientation, fever & Rt frontal lobe & S. intermedius & 28.1 & 52.2 & 18 \\
\hline $59, \mathrm{M}$ & Disorientation, seizures & Rt parietal lobe & $\begin{array}{l}\text { H. parainfluenzae, Prevotella sp, } \\
\text { F. nucleatum }\end{array}$ & 23.9 & 26.7 & 3.1 \\
\hline $3, \mathrm{~F}$ & Seizures, malaise & Lt frontal lobe & S. intermedius & 18.2 & 77.1 & 45 \\
\hline $61, \mathrm{M}$ & Hemiparesis, seizures, expressive aphasia & Lt frontal lobe & S. anginosus & 12.7 & 99.3 & 35 \\
\hline $79, \mathrm{M}$ & Ataxia, dysarthria & Rt cerebellar & S. anginosus & 8.3 & 24.7 & 14 \\
\hline $3, \mathrm{~F}$ & Seizures, malaise & Rt hemisphere† & S. intermedius & 8.2 & 71.2 & 0.8 \\
\hline $42, \mathrm{~F}$ & Headache, malaise & Rt parietal lobe & S. anginosus & 6.8 & 37.7 & 2.0 \\
\hline $45, \mathrm{~F}$ & Headache, fever, rt-sided facial paresis & Lt frontal lobe & Unknown bacterium & 4.5 & 18.7 & 3.1 \\
\hline $41, \mathrm{~F}$ & Seizures, malaise & Rt parietal lobe & S. intermedius & 2.4 & 32.9 & 8.6 \\
\hline $84, \mathrm{M}$ & Hemianopia, disorientation, seizures & Rt occipital lobe & S. intermedius & 1.7 & 27.7 & 32 \\
\hline
\end{tabular}

* Data include age and sex, symptoms prior to surgery, abscess localization (cerebral lobe or cerebellar hemisphere), bacteria in pus identified by culture and/or polymerase chain reaction, ammonia level, total concentration of amino acids in extracellular phase of pus, and abscess volume. Data reprinted with permission from Dahlberg et al.: High extracellular concentration of excitatory amino acids glutamate and aspartate in human brain abscess. Neurochem Int 69:41-47, copyright 2014, Elsevier.

$\dagger$ This patient had four abscesses in her right cerebral hemisphere, of which one in the frontal lobe was analyzed biochemically.

Streptococcus anginosus was found (Table 1). One patient had a mixed bacterial flora of Aggregatibacter aphrophilus, Parvimonas micra, Propionebacterium acnes, and Fusobacterium nucleatum; another had Haemophilus parainfluenzae, Prevotella species, and $F$. nucleatum. In 1 patient microbiological identification was not achieved.

\section{Ammonia Levels in Brain Abscesses and CSF}

The median extracellular concentration of ammonia in brain abscesses was $15.5 \mathrm{mmol} / \mathrm{L}$ (range 1.7-69.2 $\mathrm{mmol} / \mathrm{L}$; Fig. 1a). The total concentration of amino acids, which may serve as energy substrates for bacteria ${ }^{26}$ and therefore may be a source of ammonia, was 1.12-16 times higher (difference between ammonia and amino acid levels: $p=0.011$, Wilcoxon test). The level of ammonia correlated with the sum of amino acids $(r=0.56 ; p$ $=0.046$; Spearman test). The median level of individual amino acids varied from $0.43 \mathrm{mmol} / \mathrm{L}$ (arginine) to 33.5 $\mathrm{mmol} / \mathrm{L}$ (alanine). The two arginine metabolites, citrulline and ornithine, were present in pus at median values of $2.1 \mathrm{mmol} / \mathrm{L}$ and $0.54 \mathrm{mmol} / \mathrm{L}$, respectively. The levels of amino acids were similar to recently published values. ${ }^{9}$

The median glucose concentration in pus was 0 $\mathrm{mmol} / \mathrm{L}$ (range $0-2.1 \mathrm{mmol} / \mathrm{L}$ ); in 8 patients glucose could not be detected. Lactate concentration in pus was $21 \mathrm{mmol} / \mathrm{L}$ (range 3.3-26.5 mmol/L), illustrating mainly anaerobic conditions in the brain abscesses. The $\mathrm{pH}$ level was 6.8 (range 6.2-7.3), in agreement with previous measurements. ${ }^{10}$ There was no correlation between these parameters (glucose, lactate, or $\mathrm{pH}$ ) on the one hand and ammonia levels on the other $(\mathrm{p}>0.35)$.

The time from symptom onset to surgical evacuation of the abscesses ranged from 4 to 56 days (median 10 days) and did not correlate with ammonia concentration in pus $(r=0.35 ; p=0.24)$. Abscess volume ranged from 0.8 to $45 \mathrm{~cm}^{3}$ (median value $11.7 \mathrm{~cm}^{3}$; Table 1) and did not correlate with pus level of ammonia $(\mathrm{r}=-0.19 ; \mathrm{p}=0.54)$. Seizures were produced by both large and small abscesses and were seen at various concentrations of ammonia.

In CSF the concentration of ammonia was 3 orders of magnitude below that in brain abscesses, with a median value of $29 \mu \mathrm{mol} / \mathrm{L}$ (difference from abscess values, $\mathrm{p}<$ 0.001 ; Fig. 1b), which agrees with previously reported normal values for $\mathrm{CSF}^{21}$ and which is similar to normal serum values. ${ }^{12}$ The total level of amino acids was $554 \mu \mathrm{mol} / \mathrm{L}$ (median value; range 360-870 $\mu \mathrm{mol} / \mathrm{L}$ ), which was significantly lower than abscess values $(\mathrm{p}<0.001)$, with median values ranging from 0 (citrulline was not detectable) to $415 \mu \mathrm{mol} / \mathrm{L}$ (glutamine). Apart from glutamine, amino acids had median values below $30 \mu \mathrm{mol} / \mathrm{L}$.

\section{Ammonia Formation From Amino Acids by S. intermedius and S. aureus In Vitro}

$S$. intermedius, a common cause of brain abscesses, ${ }^{4,11}$ was found in 8 pus samples (Table 1). In vitro, S. intermedius formed ammonia from amino acids. Within 1 hour of incubation in a medium that contained all 20 proteinogenic amino acids plus GABA, taurine, and $\mathrm{GSH}$ at $1 \mathrm{mmol} / \mathrm{L}$, ammonia had reached a concentration of approximately $0.75 \mathrm{mmol} / \mathrm{L}$ (Fig. 2a). The concentration of arginine was reduced by $60 \%\left(p=0.10^{-6}\right)$. Arginine metabolites citrulline and ornithine were present at approximately 0.5 and $0.1 \mathrm{mmol} / \mathrm{L}$, respectively. The concentration of other amino acids was not significantly changed. At 4 hours, ammo- 


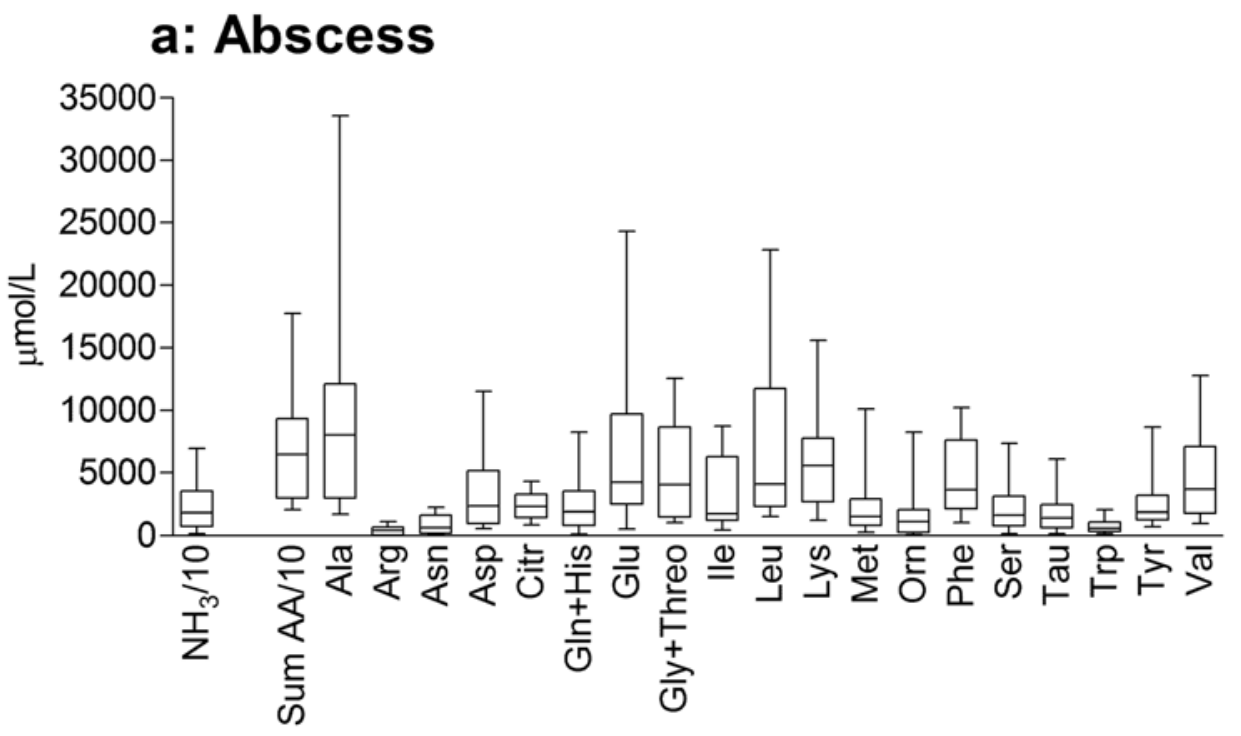

\section{b: Cerebrospinal fluid}

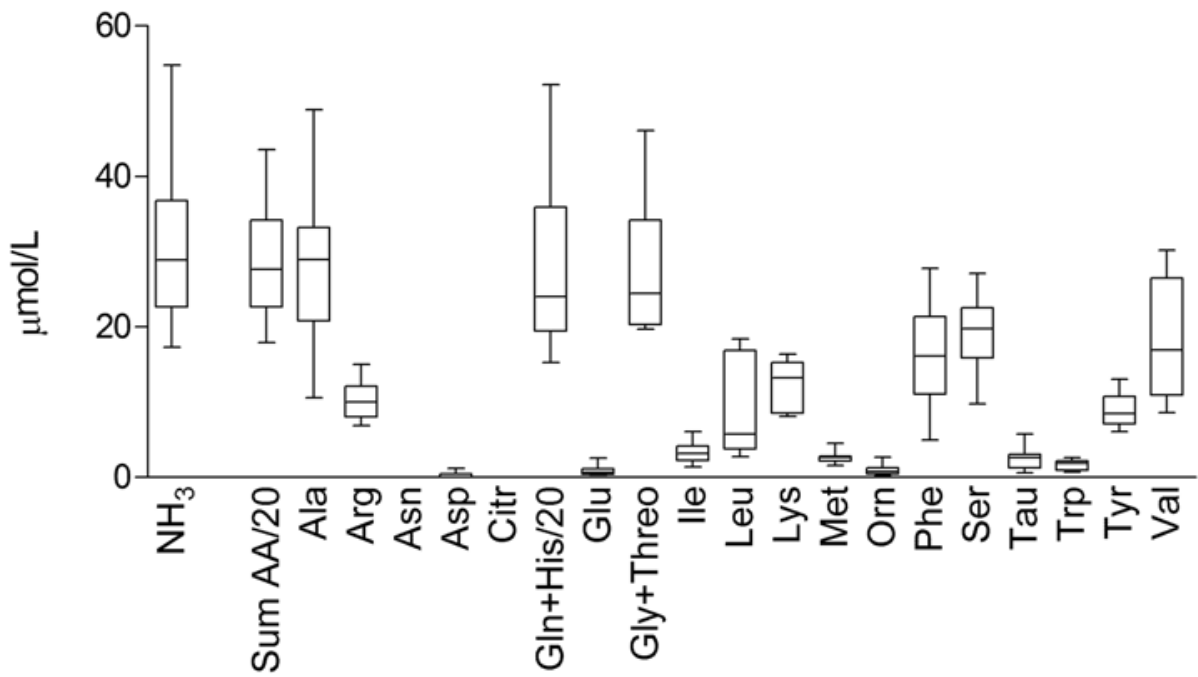

FIG. 1. Acid levels in the extracellular phase of pus from brain abscesses and CSF. a: Pus was from 14 patients with brain abscesses. b: CSF was from 10 patients undergoing external cerebroventricular drainage. The plots show the median value, with the box representing the two middle quartiles and the whiskers denoting minimum and maximum values. Values for ammonia $\left(\mathrm{NH}_{3}\right)$ and total level of amino acids (Sum AA) are divided by 10 in the upper panel; in the lower panel the total level of amino acids is divided by 20 . Amino acids were analyzed by HPLC. The HPLC procedure does not resolve glutamine and histidine or glycine and threonine, hence "GIn+His" and "Gly+Threo." Ala = alanine; Arg = arginine; Asn = asparagine; Asp = aspartate; Citr = citrulline; Gln = glutamine; Glu = glutamate; Gly = glycine; His = histidine; lle = isoleucine; Leu = leucine; Lys = lysine; Met = methionine; Orn = ornithine; Phe = phenylalanine; Ser = serine; Tau = taurine; Threo = threonine; $\operatorname{Trp}=$ tryptophan; Tyr = tyrosine; Val = valine . Reprinted with permission from Dahlberg et al.: High extracellular concentration of excitatory amino acids glutamate and aspartate in human brain abscess. Neurochem Int 69:41-47, copyright 2014, Elsevier.

nia had increased to approximately $1.5 \mathrm{mmol} / \mathrm{L}$. At this time point arginine could not be detected, but citrulline was present at approximately $0.5 \mathrm{mmol} / \mathrm{L}$ and ornithine at approximately $0.3 \mathrm{mmol} / \mathrm{L}$. The concentration of other amino acids was not significantly changed. Omission of arginine from the amino acid solution abolished ammonia production at 4 hours of incubation.

At 24 hours, ammonia was approximately $6 \mathrm{mmol} / \mathrm{L}$ in amino acid solutions incubated with $S$. intermedius (Fig. 2a). At this time point arginine, aspartate, aspara- gine, and serine were undetectable. The levels of GSH and glutamate were reduced by $35 \% \pm 8 \%$ and $56 \% \pm 6 \%$, respectively, and the levels of isoleucine, leucine, valine, tryptophan, and tyrosine were reduced by $14 \%-24 \%$ ( $p<$ 0.01 ; individual data not shown). The levels of the other measured amino acids were not significantly changed. Solutions without bacteria had unchanged concentrations of amino acids after 24 hours of incubation. After 24 hours the $\mathrm{OD}_{600}$ of $S$. intermedius had increased by $96 \% \pm 5 \%$ $\left(\mathrm{p}=10^{-9}\right)$, reflecting bacterial growth, and when the incu- 
bation media were transferred to blood agar and cultured overnight, there was massive growth of S. intermedius.

We wished to know whether different bacteria might produce ammonia through different pathways, so we analyzed ammonia formation by $S$. aureus, a common cause of brain abscesses. ${ }^{4}$ After 1 hour of incubation in the amino acid-containing medium, $S$. aureus had produced ammonia at approximately $0.2 \mathrm{mmol} / \mathrm{L}$ (Fig. $2 \mathrm{~b}$ ). The levels of alanine, arginine, and threonine tended to decrease by approximately $10 \%$ but without reaching statistical significance. At 4 hours of incubation, the concentration of ammonia was approximately $1.3 \mathrm{mmol} / \mathrm{L}$. At this time point the levels of several amino acids had decreased significantly: alanine by $13 \%$, glutamine by $20 \%$, arginine by $22 \%$, and threonine by $25 \%$. Omission of arginine from the amino acid solution reduced ammonia levels by $29 \%$ $\pm 7 \%$ at 4 hours of incubation $(\mathrm{p}=0.03 ; \mathrm{N}=4)$, whereas omission of threonine led to a $41 \% \pm 3 \%$ reduction $(\mathrm{p}=$ $0.00017 ; \mathrm{N}=4$ ). Omission of alanine or glutamine did not change ammonia formation significantly at 4 hours.

At 24 hours of incubation with $S$. aureus, the mean level of ammonia was approximately $7.5 \mathrm{mmol} / \mathrm{L}$. At this time point arginine, alanine, threonine, and glycine were undetectable. Asparagine was reduced by $90 \% \pm 2 \%$ and glutamate by $70 \% \pm 2 \%$. The concentrations of isoleucine, leucine, lysine, tyrosine, and GSH were reduced by 15\%-26\% ( $<<0.003$; individual data not shown). Unlike the situation for $S$. intermedius, the level of aspartate was reduced only by $31 \% \pm 9 \%$, whereas methionine had increased by $45 \% \pm 3 \%\left(\mathrm{p}<10^{-5}\right)$. Ornithine was present at approximately $0.2 \mathrm{mmol} / \mathrm{L}$, and citrulline could not be detected (Fig. 2b). After 24 hours, $\mathrm{OD}_{600}$ had increased by $312 \% \pm 7 \%\left(p=10^{-14}\right)$, and when the incubation media were transferred to blood agar and cultured overnight, there was massive growth of $S$. aureus.

\section{Discussion}

\section{Ammonia Is High in Brain Abscesses and May Contribute to Cerebral Symptoms}

The present study demonstrates very high concentrations of ammonia in brain abscesses in human patients; the median value was 3 orders of magnitude higher than the median value in CSF. The latter value was similar to normal values for CSF and serum. ${ }^{12,21}$ To our knowledge, this is the first report that abscesses anywhere in the body may contain ammonia at high concentrations.

A brain abscess is surrounded by a capsule composed of reactive astrocytes and fibrous tissue. ${ }^{3}$ The capsule is not a diffusion barrier, however, ${ }^{25,39}$ so ammonia would be able to diffuse from the abscess cavity into the surrounding brain tissue. Here, ammonia may contribute to edema formation $^{14,33,35}$ and interfere with neurotransmission and astrocytic potassium handling, as is illustrated in hyperammonemic states. ${ }^{14,22,34}$ Serum ammonia in patients with coma due to hepatic encephalopathy was $0.35 \mathrm{mmol} / \mathrm{L}$ or below. 2,32 The patients in the present study had pus ammonia levels well above that value. Therefore it is probable that ammonia in pus contributes to the neurological symptoms in patients with brain abscess.

Some factors may influence the degree to which am-

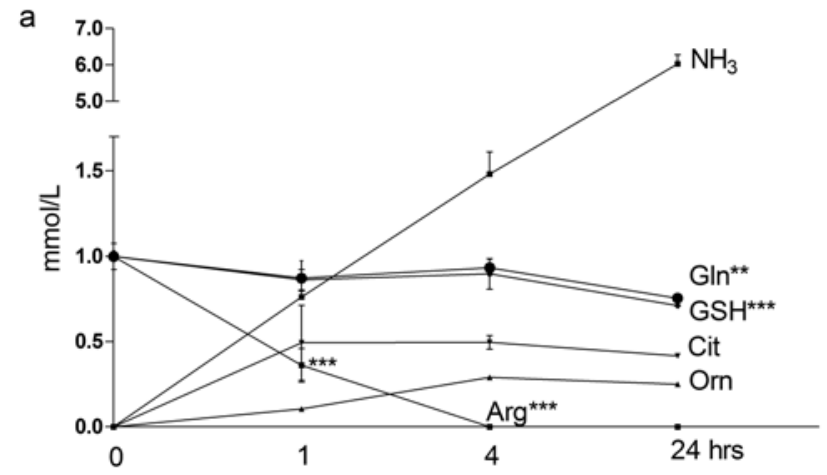

b

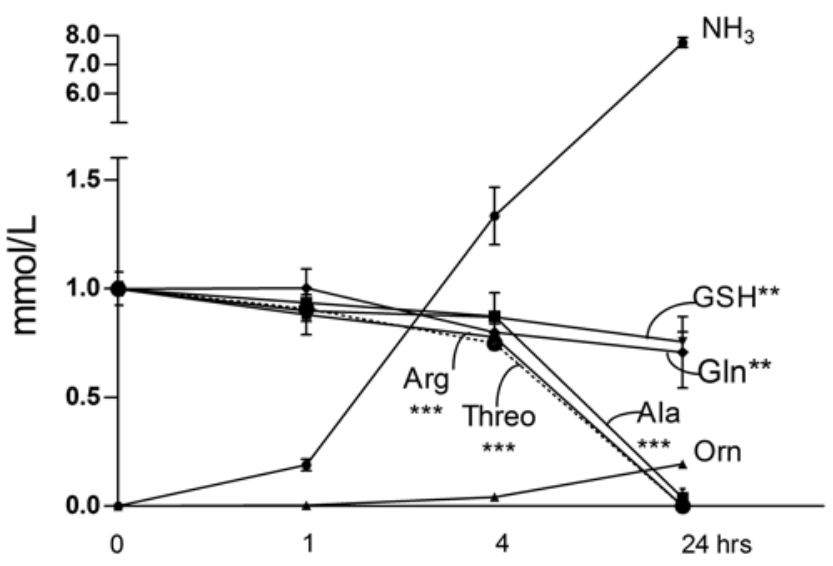

FIG. 2. Graphs showing formation of ammonia from amino acids in vitro by $S$. intermedius and $S$. aureus. The $S$. intermedius or $S$. aureus were incubated in Krebs buffer with all 20 proteinogenic amino acids plus GABA, taurine, and reduced $\mathrm{GSH}$ at $1 \mathrm{mmol} / \mathrm{L}$. The concentrations of ammonia and amino acids (including citrulline and ornithine, which were formed from arginine) were measured at 0, 1, 4, and 24 hours. Only amino acids that were significantly reduced at 4 hours are shown (except citrulline and ornithine, which increased). a: Formation of ammonia by $S$. intermedius. At 1 and 4 hours, arginine was the only amino acid that was significantly reduced, and arginine metabolites citrulline and ornithine were formed together with ammonia. Omission of arginine from the incubation medium abolished ammonia formation at 4 hours. At 24 hours arginine, asparagine, aspartate, and serine were absent, and levels of isoleucine, leucine, valine, tryptophan, and tyrosine were reduced by 14\%-24\% (not shown); these amino acids were not consumed at 1 or 4 hours. b: Formation of ammonia by $S$. aureus. The level of several amino acids was reduced after 4 hours of incubation. Omission of threonine from the incubation medium reduced ammonia formation by $41 \%$ at 4 hours, whereas omission of arginine from the incubation medium reduced ammonia formation by $29 \%$ (not shown). Omission of alanine or glutamine did not cause a significant decrease in ammonia formation at 4 hours. At 24 hours even glycine was absent, asparagine was reduced by $90 \%$, and glutamate by $70 \%$ (not shown). Data are expressed as mean \pm SD values; $N=4$ per value. Most $S D$ values have been omitted for legibility. Asterisks denote values that were different from value at 0 hour, as follows: ${ }^{* *} p<0.01$ and ${ }^{* * *} p<0.001$ (1-way ANOVA with Dunnett test for multiple comparisons). See legend to Fig. 1 for definitions of abbreviations.

monia in pus may cause neuronal dysfunction in the brain tissue surrounding the abscess. First, the volume of the abscess, together with the ammonia concentration, will determine the amount of ammonia that is available for diffusion into the surrounding brain tissue. Second, the $\mathrm{pH}$ of 
the pus will influence the diffusibility of ammonia from the abscess cavity. Ammonia as $\mathrm{NH}_{3}$ is highly diffusible across phospholipid membranes, ${ }^{1,24}$ but with a pKa of 9.2, more than $99 \%$ of the ammonia is $\mathrm{NH}_{4}{ }^{+}$at $\mathrm{pH} \mathrm{7,} \mathrm{and} \mathrm{less}$ than $1 \%$ is $\mathrm{NH}_{3}$. At lower $\mathrm{pH}$, which may occur in a brain abscess, an even greater fraction of the ammonia is protonated and has a restricted diffusibility compared with unprotonated ammonia.

It is a limitation of the present study that we do not have data on the ammonia level in the brain tissue surrounding the abscesses and that the effect of the high concentration of ammonia in pus remains a matter of speculation. Experimental studies with microdialysis of abscesses and the surrounding brain tissue may be required to address this issue. Another limitation of this study is the small number of patients, which precludes statistical evaluation of the pathogenic role of ammonia versus other factors that accompany a brain abscess, such as tissue destruction and inflammation, changes in brain architecture, and increased intracranial pressure.

\section{Possible Sources of Ammonia in a Brain Abscess}

Amino acids were probably precursors of ammonia in the brain abscesses. High concentrations of amino acids that were precursors of ammonia in vitro in this study, including arginine, threonine, alanine, and glutamine, were recently reported in pus from human brain abscesses. DNA, RNA, and other nitrogen-containing compounds could be additional important sources of ammonia. Urease-positive bacteria may cause formation of ammonia from serum urea, but of the bacteria identified in the present study, only some strains of $H$. parainfluenzae have urease activity. ${ }^{31}$ Urease is absent in $S$. intermedius and S. anginosus, ${ }^{38}$ and in A. aphrophilus, ${ }^{30} \mathrm{~F}$. nucleatum, ${ }^{16} P$. micra, ${ }^{29}$ P. acnes, ${ }^{28}$ and Prevotella species. ${ }^{36}$

Several ammonia-forming pathways may be active in a brain abscess, including ammonia formation from glutamine by phosphate-activated glutaminase, an enzyme that may originate from invading leukocytes ${ }^{5}$ or from damaged neurons. ${ }^{13}$ In the present study, S. intermedius and $S$. aureus produced ammonia at high concentrations in vitro, but seemed to do so along somewhat different pathways. Within the first 4 hours of incubation, S. intermedius primarily used arginine as a source of ammonia. This finding probably reflected an active arginine deiminase pathway, which leads to formation of ammonia, citrulline, ornithine, and adenosine 5'-triphosphate (ATP). ${ }^{8}$ Formation of citrulline from arginine entails the stoichiometric formation of 1 molecule of ammonia, whereas formation of ornithine entails the stoichiometric formation of 2 molecules of ammonia. In contrast to S. intermedius, $S$. aureus metabolized several amino acids (arginine, threonine, alanine, glutamine) within the first 4 hours of incubation, meaning that more ammonia-forming pathways were active in $S$. aureus. A preference of $S$. aureus for arginine and threonine under anaerobic conditions was recently demonstrated in vitro. ${ }^{37}$ Both $S$. intermedius and S. aureus presumably metabolize different amino acids according to their availability, but the presence of citrulline and ornithine at a high concentration in pus in this study suggested that arginine is an important source of ammonia in brain abscesses.

\section{Conclusions}

Ammonia can reach toxic levels in brain abscesses in human patients, and ammonia may contribute to the brain pathology (edema) and symptoms caused by the abscess. Brain abscesses should probably be counted among disease states that can entail a toxic effect of ammonia on the brain, along with liver failure, portocaval shunting, infections with urease-producing bacteria, and inborn errors of urea metabolism.

\section{Addendum}

Since the submission of this manuscript the authors have completed analysis of pus from 10 patients with subdural empyemas. In these 10 patients the median ammonia concentration was 318 $\mu \mathrm{mol} / \mathrm{L}$ (range 46-1038 $\mu \mathrm{mol} / \mathrm{L}$ ), in agreement with a much lower level of amino acids in this type of pus, as previously reported. ${ }^{9}$

\section{Acknowledgment}

We are grateful to Dr. S. Sterri, Norwegian Defence Research Establishment, for fruitful discussions.

\section{References}

1. Antonenko YN, Pohl P, Denisov GA: Permeation of ammonia across bilayer lipid membranes studied by ammonium ion selective microelectrodes. Biophys J 72:2187-2195, 1997

2. Bernal W, Hall C, Karvellas CJ, Auzinger G, Sizer E, Wendon J: Arterial ammonia and clinical risk factors for encephalopathy and intracranial hypertension in acute liver failure. Hepatology 46:1844-1852, 2007

3. Britt RH, Enzmann DR, Yeager AS: Neuropathological and computerized tomographic findings in experimental brain abscess. J Neurosurg 55:590-603, 1981

4. Brouwer MC, Coutinho JM, van de Beek D: Clinical characteristics and outcome of brain abscess: systematic review and meta-analysis. Neurology 82:806-813, 2014

5. Castell L, Vance C, Abbott R, Marquez J, Eggleton P: Granule localization of glutaminase in human neutrophils and the consequence of glutamine utilization for neutrophil activity. J Biol Chem 279:13305-13310, 2004

6. Chen GJ, Russell JB: Transport of glutamine by Streptococcus bovis and conversion of glutamine to pyroglutamic acid and ammonia. J Bacteriol 171:2981-2985, 1989

7. Cooper AJ: The role of glutamine synthetase and glutamate dehydrogenase in cerebral ammonia homeostasis. Neurochem Res 37:2439-2455, 2012

8. Crow VL, Thomas TD: Arginine metabolism in lactic streptococci. J Bacteriol 150:1024-1032, 1982

9. Dahlberg D, Ivanovic J, Hassel B: High extracellular concentration of excitatory amino acids glutamate and aspartate in human brain abscess. Neurochem Int 69:41-47, 2014

10. de Louvois J, Hurley R: Inactivation of penicillin by purulent exudates. BMJ 1:998-1000, 1977

11. Deutschmann MW, Livingstone D, Cho JJ, Vanderkooi OG, Brookes JT: The significance of Streptococcus anginosus group in intracranial complications of pediatric rhinosinusitis. JAMA Otolaryngol Head Neck Surg 139:157-160, 2013

12. Diaz J, Tornel PL, Martinez P: Reference intervals for blood ammonia in healthy subjects, determined by microdiffusion. Clin Chem 41:1048, 1995 (Letter)

13. Driscoll BF, Deibler GE, Law MJ, Crane AM: Damage to neurons in culture following medium change: role of glutamine and extracellular generation of glutamate. J Neurochem 61:1795-1800, 1993 
14. Felipo V, Butterworth RF: Neurobiology of ammonia. Prog Neurobiol 67:259-279, 2002

15. Garg M, Gupta RK, Husain M, Chawla S, Chawla J, Kumar $\mathrm{R}$, et al: Brain abscesses: etiologic categorization with in vivo proton MR spectroscopy. Radiology 230:519-527, 2004

16. Gharbia SE, Shah HN: Fusobacterium nucleatum subsp. fusiforme subsp. nov. and Fusobacterium nucleatum subsp. animalis subsp. nov. as additional subspecies within Fusobacterium nucleatum. Int J Syst Bacteriol 42:296-298, 1992

17. Gonzalez SV, Nguyen NH, Rise F, Hassel B: Brain metabolism of exogenous pyruvate. J Neurochem 95:284-293, 2005

18. Görg B, Schliess F, Häussinger D: Osmotic and oxidative/ nitrosative stress in ammonia toxicity and hepatic encephalopathy. Arch Biochem Biophys 536:158-163, 2013

19. Grand S, Passaro G, Ziegler A, Estève F, Boujet C, Hoffmann $D$, et al: Necrotic tumor versus brain abscess: importance of amino acids detected at ${ }^{1} \mathrm{H}$ MR spectroscopy-initial results. Radiology 213:785-793, 1999

20. Häberle J: Clinical and biochemical aspects of primary and secondary hyperammonemic disorders. Arch Biochem Biophys 536:101-108, 2013

21. Huizenga JR, Teelken AW, Tangerman A, de Jager AE, Gips $\mathrm{CH}$, Jansen PL: Determination of ammonia in cerebrospinal fluid using the indophenol direct method. Mol Chem Neuropathol 34:169-177, 1998

22. Izumi Y, Svrakic N, O'Dell K, Zorumski CF: Ammonia inhibits long-term potentiation via neurosteroid synthesis in hippocampal pyramidal neurons. Neuroscience 233:166173,2013

23. Jacobsen W, Webb M: The two types of nucleoproteins during mitosis. Exp Cell Res 3:163-167, 1952

24. Litman T, Søgaard R, Zeuthen T: Ammonia and urea permeability of mammalian aquaporins. Handb Exp Pharmacol 2009:327-358, 2009

25. Lo WD, Wolny A, Boesel C: Blood-brain barrier permeability in staphylococcal cerebritis and early brain abscess. J Neurosurg 80:897-905, 1994

26. Milligan TW, Doran TI, Straus DC, Mattingly SJ: Growth and amino acid requirements of various strains of group B streptococci. J Clin Microbiol 7:28-33, 1978

27. Mistry RD, Marin JR, Alpern ER: Abscess volume and ultrasound characteristics of community-associated methicillinresistant Staphylococcus aureus infection. Pediatr Emerg Care 29:140-144, 2013

28. Moss CW, Dowell VR Jr, Lewis VJ, Schekter MA: Cultural characteristics and fatty acid composition of Corynebacterium acnes. J Bacteriol 94:1300-1305, 1967

29. Murphy EC, Frick IM: Gram-positive anaerobic cocci-commensals and opportunistic pathogens. FEMS Microbiol Rev 37:520-553, 2013

30. Nørskov-Lauritsen N, Kilian M: Reclassification of Actinobacillus actinomycetemcomitans, Haemophilus aphrophilus, Haemophilus paraphrophilus and Haemophilus segnis as Aggregatibacter actinomycetemcomitans gen. nov., comb. nov., Aggregatibacter aphrophilus comb. nov. and Aggregatibacter segnis comb. nov., and emended description of Aggregatibacter aphrophilus to include V factor-dependent and V factor-independent isolates. Int J Syst Evol Microbiol 56:2135-2146, 2006
31. Oberhofer TR, Back AE: Biotypes of Haemophilus encountered in clinical laboratories. J Clin Microbiol 10:168-174, 1979

32. Ong JP, Aggarwal A, Krieger D, Easley KA, Karafa MT, Van Lente F, et al: Correlation between ammonia levels and the severity of hepatic encephalopathy. Am J Med 114:188-193, 2003

33. Rama Rao KV, Jayakumar AR, Norenberg MD: Brain edema in acute liver failure: mechanisms and concepts. Metab Brain Dis 29:927-936, 2014

34. Rangroo Thrane V, Thrane AS, Wang F, Cotrina ML, Smith NA, Chen M, et al: Ammonia triggers neuronal disinhibition and seizures by impairing astrocyte potassium buffering. Nat Med 19:1643-1648, 2013

35. Rovira A, Alonso J, Córdoba J: MR imaging findings in hepatic encephalopathy. AJNR Am J Neuroradiol 29:1612_ 1621,2008

36. Sakamoto M, Suzuki M, Huang Y, Umeda M, Ishikawa I, Benno Y: Prevotella shahii sp. nov. and Prevotella salivae sp. nov., isolated from the human oral cavity. Int J Syst Evol Microbiol 54:877-883, 2004

37. Sun JL, Zhang SK, Chen JY, Han BZ: Metabolic profiling of Staphylococcus aureus cultivated under aerobic and anaerobic conditions with ${ }^{(1)} \mathrm{H}$ NMR-based nontargeted analysis. Can J Microbiol 58:709-718, 2012

38. Whiley RA, Beighton D: Emended descriptions and recognition of Streptococcus constellatus, Streptococcus intermedius, and Streptococcus anginosus as distinct species. Int J Syst Bacteriol 41:1-5, 1991

39. Yamamoto M, Jimbo M, Ide M, Tanaka N, Umebara Y, Hagiwara S: Penetration of intravenous antibiotics into brain abscesses. Neurosurgery 33:44-49, 1993

40. Zhou Y, Holmseth S, Guo C, Hassel B, Höfner G, Huitfeldt HS, et al: Deletion of the $\gamma$-aminobutyric acid transporter 2 (GAT2 and SLC6A13) gene in mice leads to changes in liver and brain taurine contents. J Biol Chem 287:35733-35746, 2012

\section{Disclosure}

This study was supported by the Norwegian Chapter of the International League Against Epilepsy; Reberg's Trust Fund, Norway; The Norwegian Health Association (Grant No. 1513); and the Norwegian Epilepsy Society.

\section{Author Contributions}

Conception and design: all authors. Acquisition of data: all authors. Analysis and interpretation of data: Dahlberg, Hassel. Drafting the article: Dahlberg, Hassel. Critically revising the article: all authors. Reviewed submitted version of manuscript: all authors. Approved the final version of the manuscript on behalf of all authors: Hassel. Statistical analysis: Dahlberg, Hassel. Study supervision: Hassel.

\section{Correspondence}

Bjørnar Hassel, Norwegian Defence Research Establishment (FFI), N-2027 Kjeller, Norway. email: bjornar.hassel@ffi.no. 